\section{CARREIRA DOCENTE EM EDUCAÇÃO FÍSICA: HISTÓRIA DE VIDA DE UMA PROFESSORA EMÉRITA}

\author{
TEACHING CAREER IN PHYSICAL EDUCATION: THE LIFE HISTORY OF AN \\ EMERITUS PROFESSOR
}
CARRERA DOCENTE EN EDUCACIÓN FÍSICA: HISTORIA DE VIDA DE UNA PROFESORA EMÉRITA

\author{
Luana Jaqueline da Silva*, Alexandra Folle*, Gelcemar Oliveira Farias*, \\ Alzira Isabel da Rosa**
}

\begin{abstract}
Palavras chave:
Escolha da

profissão.

Estágios do ciclo de

vida.

Docentes.

EducaçãoFísica e

Treinamento.

Resumo: Este estudo analisou as implicações dos percursos pessoal, formativo e profissional no desenvolvimento da carreira docente de uma professora de Educação Física na fase emérita. Na coleta das informações utilizou-se uma entrevista semiestruturada, a qual foi analisada pela técnica de análise de conteúdo. A história de vida da professora ilustra os entrelaçamentos dos percursos de desenvolvimento, em que o percurso pessoal é marcado pelo afastamento da família em prol dos estudos e do trabalho e o formativo representado pelo encantamento com o curso de formação inicial e pela constante atualização por meio dos processos de formação continuada em serviço e em prol da melhoria da prática pedagógica, enquanto o percurso profissional é sustentado pelos momentos significativos vivenciados ao longo de cinco ciclos de vida docente.
\end{abstract}

Keywords Career Choice. Life Cycle Stages. Faculty. Physical Education and Training. Elección de profesión. Fases del Ciclo de Vida.

Docentes.

Educación Física y Entrenamiento.
Abstract: This study examined the implications of personal, training and professional aspects for career development of a Physical Education teacher at the Emeritus stage. Data collection used a semi-structured interview was subjected to content analysis. The teacher's life history illustrates the intertwining of development paths in which her personal journey is marked by being away from her family for studies and work and by professional improvement represented by her fascination with the initial training course and constant updating through continued education processes in order to improve teaching practice, while her career is supported by significant moments experienced over the five cycles of teaching life.

Resumen: Este estudio analizó las implicaciones de los recorridos personal, formativo y profesional en el desarrollo de la carrera docente de una profesora de Educación Física en la fase emérita. Para recolectar informaciones se utilizó una entrevista semiestructurada, la cual fue analizada por la técnica de análisis de contenido. La historia de vida de la profesora ilustra cómo se entrelazan los recorridos del desarrollo, donde el recorrido personal es marcado por el alejamiento de la familia por los estudios y el trabajo y el recorrido formativo, representado por el encantamiento con el curso de formación inicial y por la constante actualización a través de procesos de formación continua en servicio y buscando la mejoría de la práctica pedagógica, mientras el recorrido profesional es sustentado por los momentos significativos vividos a lo largo de cinco ciclos de vida docente.
*Universidade do Estado de Santa Catarina. Florianópolis, SC, Brasil. E-mail:luh_jaquesilva@hotmail.com; afolle_12@ hotmail.com; fariasgel@ hotmail.com

** Prefeitura Municipal de São José. São José, SC, Brasil. E-mail:alzirarosa2005@yahoo.com.br

Recebido em: 12-08-2016 Aprovado em: 08-01-2018

$\mathrm{DOl}$ http://dx.doi.org/10.22456/1982-8918.66937 (c) (1) (8) Licence 


\section{INTRODUÇÃOO}

No âmbito educacional, investigações referentes à história de vida de professores têm sidoconsideradascomoimportantes para a compreensão e para reflexão do docente no contexto escolar. Nesse cenário, a literaturana área da Educação tem sido enriquecida por obras e estudos sobre a vida de professores, sua carreira e seu desenvolvimento profissional, recolocando estes no centro de problemáticas investigativas (ALMEIDA; FENSTERSEIFER, 2007; SANTOS; BRACHT; ALMEIDA, 2009; FOLLE et al., 2009; FOLLE; NASCIMENTO, 2010; ROSSI; HUNGER, 2012; NUNES; GODOI, 2013).

A reflexão sobre 0 desenvolvimento profissional destaca as experiências de vida dos professores como edificadoras de muitos dos seus saberes, destacando-se que esse desenvolvimento não pode ser considerado como algo definitivo, mas algo em constante evolução (HUBERMAN, 2000). Nessa perspectiva, compreende-se que o desenvolvimento profissional resulta da ação conjunta de três processos, quais sejam: pessoal; aquisição de competências no ensino; e socialização profissional (GONÇALVES, 2000).

No intuito de contribuir com uma análise profunda e detalhada desses processos e dos diferentes momentos vivenciados ao longo da carreira docente, investigadores têm proposto distintos modelos para classificar os ciclos, os estágios ou as fases da vida profissional, pelos quais passam os professores, durante as suas trajetórias (NASCIMENTO; GRAÇA, 1998; GONÇALVES, 2000; HUBERMAN, 2000; STEFFY et al., 2000; FARIAS; NASCIMENTO, 2012). Apesar das diferenças encontradas nas propositivas, em termos de quantidade, duração e nomenclatura das fases, algumas similaridades podem ser observadas entre elas.

No tocante a uma fase inicial, percebe-se que os professores apresentam características de sobrevivência na profissão, atreladas ao choque com a realidade ou à descoberta, vinculada ao entusiasmo inicial com a docência. Em fases intermediárias, percebe-se uma "tomada de decisão", a qual ocasiona um comprometimento definitivo com a profissão e um sentimento de confiança mais apurado em suas práticas pedagógicas, além da busca pela diversificaçãoda carreira, assumindo cargos administrativos ou posicionamento de passividade anteo agir pedagógico. Em uma fase final, percebe-se um "desinvestimento sereno" (sentimento de satisfação e de realização com a profissão e sua trajetória) ou um "desinvestimento amargo" (ansiedade pela aposentadoria e fim da carreira), demarcado pelas experiências negativas das fases anteriores (NASCIMENTO; GRAÇA, 1998; GONÇALVES, 2000; HUBERMAN, 2000; STEFFY et al., 2000; FARIAS; NASCIMENTO, 2012). Por fim, a fase eméritaé marcada como uma fase de realização na docência, na qual os professores aposentados escolhem continuar sua trajetória profissional após a aposentadoria, permanecendo vinculados à área educacional (STEFFY et al., 2000). Essa característica está presente em docentes que durante os percursos formativo e profissional tiveram experiências significativas e se consolidaram na prática pedagógica, resultando no desejo de continuidade das atividades docentes.

Entretanto, para compreender os processos de desenvolvimento profissional, o olhar do investigador deve estar voltado para os percursos pessoal, formativo e profissional (JUNGES, 2006). No que tange ao percurso pessoal, ressaltam-se as experiências vividas na infância $e$ na adolescência, considerando que as experiências de vida e 0 ambiente sociocultural em que os professores estão inseridos refletem suas decisões, opções e prática profissional. Por sua vez, enquanto o percurso formativo engloba as experiências vividas na formação básica, inicial 
e continuada, o percurso profissional envolve a escolha pela docência, as representações que o professor tem de si mesmo comodocente, de sua inserção no trabalho e da consciência da função social de sua profissão (HUTCHINSON; BUSCHNER, 1996; JUNGES, 2006).

Nesse cenário, os estudos das histórias de vida se tornam de suma relevância no contexto investigativo da formação e do desenvolvimento profissional docente. Além disso, evidencia-se que, apesar da iniciativa de investigações desenvolvidas com professores de Educação Física (FOLLE et al., 2009; SANTOS; BRACHT; ALMEIDA, 2009; FOLLE; NASCIMENTO, 2010; FARIAS; NASCIMENTO, 2012; ROSSI; HUNGER, 2012) no território brasileiro, estes estudos têm sido desenvolvidos com professores iniciantes, em diferentes fases ou em processo de aposentaria, sendo escassas pesquisas conduzidas com professores aposentados e que permaneceram ou retornaram para a docência após aposentadoria em uma rede de ensino (SANTOS; BRACHT; ALMEIDA, 2009).

Neste cenário, destaca-se ainda que tais estudos sobre o desenvolvimento profissionaltêm identificado que os professores de Educação Física não perspectivam retornar à sala de aula após a aposentadoria, o que ressalta a importância de investigações sobre as experiências que têm levado poucos professores a se tornarem docentes eméritos. Para tanto, o presente estudo visa contribuir com a ampliação da compreensão da história de vida de professores aposentados e que continuam atuantes na docência, ao analisar as implicações dos percursos pessoal, formativo e profissional no desenvolvimento da carreira docente de uma professora de Educação Física na fase emérita.

\section{DECISÕES METODOLÓGICAS}

Esta pesquisa se caracteriza como um estudo de histórias de vida, com abordagem qualitativa das informações. A investigação das histórias de vida se assinala como um depoimento coletado por meio de entrevista ou anotações pessoais, tendo como propósito compreender uma trajetória de vida, ou fragmentos dela, e visando descrever ou restabelecer fases históricas marcadas na vida dos sujeitos (SOUZA, 2006).

Participou da investigação uma professora de Educação Física, aposentada após 26 anos de carreira na rede estadual de ensino de Santa Catarina e que atua há14 anos como professora efetiva na rede municipal de São José/SC. A professora encontra-se, assim, na fase denominada de emérita (STEFFYet al.,2000), uma vez que ela, após se aposentar, optou por manter seu vínculo profissional com o ensino básico. Destaca-se que esta foi a única professora aposentada e atuante em sala de aula na rede municipal de ensino investigada. Paracoleta das informações sobre a história de vida docente da professora, realizou-seuma entrevista semiestruturada, elaborada a partir dos seguintes temas geradores: identificação (idade, estado civil, formação, atuação profissional); percurso formativo (educação básica, formação inicial e formação continuada); aderência à profissão e ao espaço de intervenção (escolha profissional, espaço de intervenção de preferência, motivos de permanência e/ou afastamento da carreira docente); ciclos da carreira docente (transição estudante-professor, efetivação, momentos marcantes, expectativas, cargos administrativos, aposentadoria).

A pesquisa foi aprovada pelo Comitê de Ética em Pesquisa com Seres Humanos da Universidade do Estado de Santa Catarina (Parecer n.1.299.328). O encontro com a professora foi realizado na instituição de ensino em que ela atua, no período matutino, durante sua hora- 
atividade. A docente assinou o Termo de Consentimento Livre e Esclarecido e respondeu, inicialmente, aos dados de identificação e, posteriormente, narrou sua história a partir das temáticas elencadas. A entrevista foi realizada por uma única investigadora e durou 1 hora e 8 minutos, sendo a captação do áudio realizada por meio de gravador. A transcrição do material gravado foi realizada na íntegra e enviada à docente para a validação da transcrição de suas falas.

A análise das informações foi realizada por meio da técnica de Análise de Conteúdo, utilizando-se o software NVIVO, versão 9.2. As etapas da técnica de Análise de Conteúdo adotadas seguiram as indicações de Campos (2004): fase de pré-exploração do material (leitura flutuante do corpus da entrevista); seleção das unidades de análise (temasadvindos de escolha própria do pesquisador, vislumbrada através dos objetivos de sua pesquisa,dos indícios levantados emseu contato com o material estudado e das teorias embasadoras); processo decategorização e subcategorização (grandes enunciados que segundo seu grau de intimidadeouproximidadeexprimem significados e elaborações importantes que atendam aos objetivos de estudo). As categorias de análise elencadas para o estudo foram:

- Percurso Pessoal: família (presença de irmãos e sobrinhos na área da educação, sem cônjuge, sem filhos), moradias (família, colegas, amigas);

- Percurso Formativo: educação básica (contribuição para a escolha do curso); formação inicial (encantamento com o curso; desencanto no estágio, estágio não remunerado), formação continuada (motivação para continuar estudando, subsídios teóricos, cursos de especialização e de atualização);

- Percurso Profissional: Entrada - 1-4 anos (relação com a formação inicial, choque com o real, tomada de decisão); Consolidação das Competências (5-9 anos) (realização na escola e no ambiente de trabalho); Afirmação e Diversificação - 10-19 anos (função administrativa, atividades diversificadas, percepção de autossuperação, sentimento de competência), Renovação - 20-27 anos (encantada com a docência, renovação da atuação profissional, aposentadoria, perda de identidade, adoecimento); Emérita - 28 anos (desejo de permanecer ativa, realização profissional).

\section{RESULTADOS}

A professora de Educação Física emérita nasceu no ano de 1961 em uma cidade do interior do Rio Grande Sul, onde viveu com seus pais e sete irmãos, em um sítio, até os 11 anos. Com essa idade, para poder continuar estudando, mudou-se com os irmãos para a região central da cidade, onde realizou o "ginásio"(anos finais do ensino fundamental) e o "2ํ Grau" (ensino médio). Após a aprovação no vestibular, mudou-se para Santa Maria/RS, morando com colegas e amigos até concluir o curso de formação inicial em Educação Física.

No início da carreira, pela dificuldade de conseguir emprego, transferiu-se para cidades do interior da Região Oeste de Santa Catarina e,posteriormente, fixou endereço em São José/ SC, cidade onde reside atualmente. No início da estada em São José, morou sozinha por 15 anos. Atualmente, uma de suas irmãs mora em sua casa, provisoriamente (Figura 1). As figuras a seguir representam os percursos da professora investigada, permitindo compreender cronologicamente seus percursos pessoal, formativo e profissional. 
Figura 1 - Percurso pessoal da professora de Educação Física

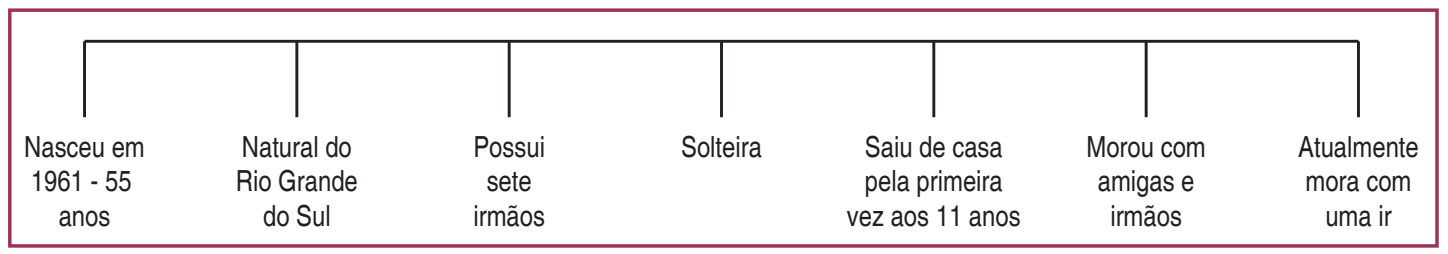

Fonte: dados da pesquisa

Na família, o pai era agricultor e a mãe dona de casa, enquanto o irmão mais velho fez magistério e formou-se em Biologia. A professora destaca que, após a sua formação em Educação Física, algumas irmãs e sobrinhos também buscaram esse curso no ensino superior e seguiram carreira na área da educação. Na sua trajetória pessoal, ela revela ainda que não foi casada e não teve filhos.

O percurso formativo da professora revela que ela concluiu todos os níveis de ensino dentro dos prazos mínimos de formação, exigidos pelo currículo daquele momento histórico da educação na realidade brasileira (Figura 2).

Figura 2 - Percurso formativo da professora de Educação Física

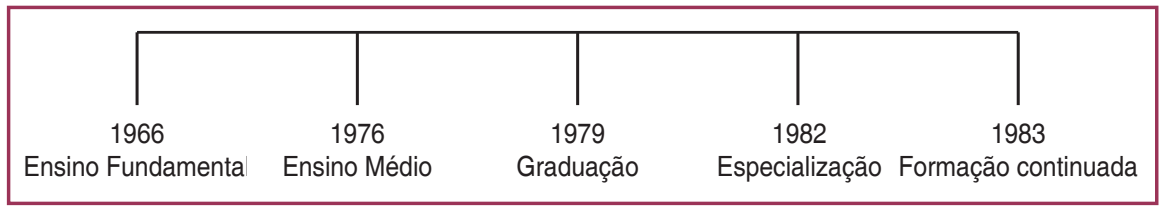

Fonte: dados da pesquisa

O relato oral da professora emérita revelou que suas experiências com o esporte (atletismo) na Educação Física extracurricular influenciaram a escolha, em segunda opção, pelo curso de formação inicial em Educação Física, mesmo que sua primeira opção tivesse sido o curso de Farmácia, em virtude de ela ter realizado o ensino médio técnico em Análises Químicas. As vivências ao longo do curso superior promoveram um encantamento com a Educação Física, principalmente as experiências positivas nas disciplinas cursadas. No entanto, as primeiras vivências no Estágio Curricular Supervisionado, realizado em escola pública, promoveram um desencanto com a docência, o que a levou a se questionar se, realmente, ser professora seria seu objetivo profissional. Situação esta que foi superada por meio de uma nova experiência, que foi obtida em estágio não remunerado realizado em uma escola privada, surgindo assim os primeiros sentimentos de realização na docência com crianças dos anos iniciais do ensino fundamental.

$\mathrm{Na}$ continuidade do seu percurso formativo, relatou a permanente motivação para os estudos, por meio de formação continuada, iniciada no curso de especialização Lato Sensu em Recreação e Lazer, o qual foi realizado em paralelo com o último ano da formação inicial, e de forma contínua por meio de cursos de capacitação profissional em diferentes contextos e de formação continuada oferecida pelas redes de ensino.

O percurso profissional da professora foi marcado por cinco ciclos da carreira docente: entrada; consolidação das competências profissionais; afirmação e diversificação; renovação; e emérita (Figura 3). 
Figura 3 - Percurso profissional da professora de Educação Física

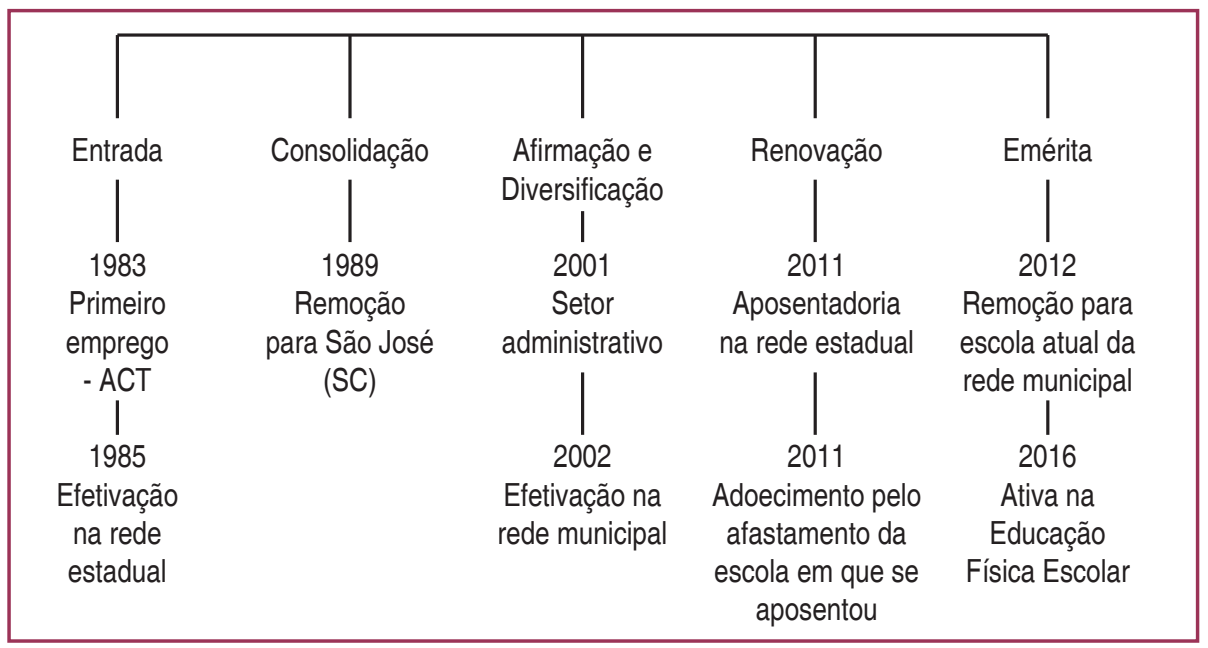

Fonte: dados da pesquisa

O ciclo de Entrada na Carreira é descrito pela professora como um momento marcante em sua trajetória. No entanto, ela ressalta que, na relação entre o ingresso no campo de trabalho e a formação inicial, as experiências vividas no curso de licenciatura em Educação Física não contribuíram de forma positiva para sua inserção na escola. Os primeiros anos de docência foram marcados pelo "choque com a realidade" devido à frustração causada pela obrigatoriedade de ter que trabalhar o bloco de quatro modalidades esportivas (futebol, voleibol, basquetebol e handebol) e com o esporte de rendimento no ambiente escolar, além de participar com os alunos de eventos esportivos em nível escolar. Outros fatores agravantes foram as condições de trabalho, em que o espaço físico e material eram escassos ou não existiam, dificultando a prática profissional. Para superar essa dificuldade inicial, realizou cursos de atualização no âmbito esportivo e tentou vincular as aprendizagens com o âmbito escolar, bem como passou a construir materiais e organizar espaços adaptados para 0 desenvolvimento das aulas.

O choque com a realidade foi marcado também pela dificuldade em conseguir o primeiro emprego na cidade em que morava. Fato este que motivou uma mudança de cidade e de estado em busca de oportunidades de emprego, a qual possibilitou 0 ingresso na docência como professora Admitida em Caráter Temporário (ACT). No ano seguinte, a efetivação se fez por meio de concurso público, em que a professora passou a fazer parte do quadro de efetivos da escola em que atuava como ACT, momento este descrito com grande alegria e sentimento de conquista pessoal e profissional: "Foi ótimo. Fiquei em segundo lugar, em um concurso com muitas pessoas. Fiquei na mesma escola que eu já estava como ACT [...]. Um motivo de vitória [...]. Realizada, eu venci a batalha de passar em um concurso [...]. Fui aprovada com mérito ainda [...]".

O segundo ciclo da carreira, Consolidação das Competências Profissionais, foi marcado pela mudança para o litoral catarinense e a atuação com os primeiros anos do ensino fundamental na nova escola. Foi nessa faseem que a professora experienciou pela primeira vez o sentimento de realização profissional e de satisfação em atuar com determinado nível de ensino: "[...] eu cheguei nessa escola, que só tinha o fundamental 1, e foi onde me realizei. Quando você sente prazer em estar na escola e não há aquela cobrança de ter que apresentar a equipe, ter que jogar, ter que ganhar medalha, foi onde me encontrei". 
O ciclo de Afirmação e Diversificação na Carreira proporcionou momentos decisivos ante novos desafios profissionais. A docente teve a oportunidade de ampliar o convívio com os colegas de trabalho e diversificar práticas coletivas (gincanas, teatros, festas) promovidas em parceria com outros professores. Estas lembranças foram narradas com carinho, demonstrando que $o$ início desta fase foi vivenciado de forma significativa no percurso profissional e pessoal da professora:

Uma vez fizemos [...] uma peça de teatro surpresa para as crianças. Eu e mais uma professora fizemos Chapeuzinho Vermelho. Os serventes da escola eram muito atuantes, eles fizeram casinha da vovó, floresta, todo mundo se envolveu [...]. Falamos para as crianças que elas teriam uma surpresa, que viriam uns atores apresentar uma peça [...]. Quando entramos, eles ficaram empolgados porque eram as professoras [...].

$\mathrm{Na}$ etapa final deste ciclo, a professora teve que cumprir carga horária nas rotinas administrativas da secretaria escolar, diversificando assim sua função na escola. Além disso, houve o desafio de atuar com turmas de ensino médio no período noturno, exigindo dela alterações em suas opções didático-pedagógicas e resultando no sentimento de autossuperação e realização profissional. Para finalizar os marcos deste ciclo, ressalta-se a importância atribuída pela professora à sua efetivação na rede municipal de São José, momento que significou uma nova conquista profissional no rolde sua trajetória.

O momento marcante do ciclo de Renovação na Carreira se deu pela aposentadoria na rede estadual de ensino, que desencadeou um sentimento profundo de tristeza e causou, até mesmo, adoecimento (emocional) em virtude de ter que se afastar de um espaço que ela considerava como seu, uma sua conquistasua. A aposentadoria representou assim a perda de uma identidade construída ao longo de sua história no magistério. Seu depoimento revelou uma entonação de tristeza e saudade dos momentos vividos na escola, apresentando certa resistência em deixar sua trajetória, edificada na escola, para trás:

[...] parecia que estavam pegando o que era meu, eu sofri muito [...]. Eu ia lá e parecia que tinham pegado o que era meu, aquilo era meu e quando eu cheguei lá e vi que tinham arrombado meu armário e tiraram minhas coisas de dentro, eu disse: 'Como vocês fizeram isso? Esse armário era meu!'.

Para não se afastar definitivamente da carreira docente e continuar sua trajetória profissional, a professora seguiu trabalhando na rede municipal, da qual fazia parte do quadro de docentes efetivos. Em consonância com o exposto pela docente, revela-se a eminência do sentimento de angústia pelo encerramento da trajetória vivenciada, o que ressalta a sensibilidade de permanecer na carreira, extrapolando o que é retratado sobre o desenvolvimento profissional, em que a aposentadoria surge como uma expectativa de finalização de uma carreira. A continuidade da vida profissional, neste caso específico, pode ter sido um dos fatores de superação do sentimento de adoecimento emocional (afastamento de sua conquista), em virtude das competências e do sentimento de contemplação na intervenção profissional manifestada pela professora.

O sentimento de realização profissional norteia atualmente a fase Emérita na Carreira. A estabilidade financeira, a carga horária reduzida e a proximidade da escola de sua residência proporcionam à entrevistada o sentimento de segurança e de desejo em continuar sua intervenção profissional, além da atuação com o nível de ensino de sua preferência, os anos iniciais do Ensino Fundamental. O gosto pela profissão e o prazer em lecionar ofuscam, assim,o 
desejo de aposentadoria definitiva, momento este que não é perspectivado ou desejado pela professora emérita: "[...]não consigo me imaginar sem este trabalho. Acho que até onde eu tiver forças físicas e emocional, vou continuar trabalhando".

Para tanto, nesse momento da carreira docente, a professora evidencia estar realizada profissionalmente e deseja permanecer ativa na profissão. Por outro lado, no caminho do findar de sua trajetória, revela que, após a segunda aposentadoria, buscará atividades para ocupar seu tempo livre, visando amenizar o sentimento de perda vivenciado na primeira ruptura com a docência:

Então, o que vou fazer de manhã? [...] vou fazer algum curso de formação, em inglês ou alguma coisa que eu não fiz. Mas, até o momento, não consigo pensar, nem me imaginar sem esta carga horária. Ainda tenho doze anos pela frente, se quiser ter uma aposentadoria integral.

As informações pertinentes aos percursos vivenciados na trajetória da professora investigada evidenciam que sua formação revelou um percurso linear, similar ou esperado para professores da Educação Básica (educação básica, formação inicial, especialização, cursos de aperfeiçoamento). Por sua vez, seu percurso pessoal refletiu 0 afastamento dos familiares em prol dos percursos formativos e profissionais e pelo incentivo nas escolhas de seus familiares como profissionais da Educação, enquanto seu percurso profissional elucidou avanços e retrocessos em sua trajetória, dependendo de como ela enfrentou os desafios com os quais se defrontou.

\section{DISCUSSÃO}

As informações obtidas na narrativa da professora de Educação Física emérita revelaram as implicações dos percursos pessoal, formativo e profissional no desenvolvimento da carreira docente vivenciada ao longo de 33 anos de magistério público, tanto em rede estadual quanto em rede municipal de educação.

$O$ percurso pessoal evidenciou a necessidade de afastamento do ambiente familiar em prol dos estudos e, posteriormente, da profissão, ou seja, este percurso desde muito cedo foi mais afetado do que afetou os demais percursos. De modo similar, relatos de professores de outras áreas do conhecimento revelaram que suas formações pessoais foram marcadas pela infância no meio rural de cidade interiorana, com a convivência de muitos irmãos e com o afastamento do lar para dar continuidade àformação acadêmica, após conclusão do "ensino primário" (anos iniciais) (KOCHHANN, 2000; ROCKENBACH, 2000). Monteiro e Mizukami (2002) refletem tambémque a realidade de vida de muitos professores realmente não é fácil, pois assim como ocorreu com a professora emérita, muitos docentes, em início de carreira, precisam se mudar para outras cidades, especialmente as localizadas no interior, para assim conseguirem seus primeiros empregos, o queos leva a manterem suas vidas longe das rotinas de seus familiares.

Ao contrário do percurso pessoal da professora emérita, que é solteira e sem filhos, o da professora de Educação Física aposentada investigada por Betti e Mizukami (1997) demonstrou que o casamento e o nascimento dos quatro filhos influenciaram sua trajetória profissional, haja vista queem muitos momentos tal professora precisou encerrar suas aulas ou permaneceu na escola ansiosa, em virtude do desejo de retornar para casa e estar com seus 
filhos. Nesse sentido, constata-se que,na análise do desenvolvimento da carreira docente, é perceptível a existência dediferenças entre os mais jovens e os experts,entre homens e mulheres, entre casados e solteiros.

O percurso formativo foi marcado pela escolha do curso de Educação Física por meio das experiências esportivas vivenciadas na Educação Básica. Nesse sentido, assim como reportadopela emérita, outros professores também têm relatado que o gosto e a identificação com os esportesforam os fatores primordiais para a escolha da formação inicial nesta área (HUTCHINSON; BUSCHNER, 1996; HEBERT; WORTHY, 2001; FOLLE et al., 2009;SANTOS; BRACHT; ALMEIDA, 2009; MACHADO et al., 2010; BENITES; SOUZA NETO, 2011; NUNES; GODOI, 2013). Similarmente aos achados desta investigação, outros estudos têm indicado que, apesar do encantamento com o curso de Educação Física, alguns estudantes e docentes vivenciaram um desencanto com o curso ao ingressarem nos Estágios Curriculares Supervisionados (FOLLE; NASCIMENTO, 2010; MOLETTA et al., 2013; MEDEIROS et al., 2014).

Em muitos casos, fica evidente a percepção de que os estágios não estão sendo suficientes para possibilitar a compreensão sobre a complexidade da realidade educacional. No entanto, jovens professores podem não ter maturidade para perceber que "[...] o momento de realização dos estágios é apenas um processo [...] e que possivelmente não dará conta de estabelecer as trocas com o contexto e a cultura escolar" (MEDEIROS et al., 2014, p. 39). Não obstante, destaca-se queo período de escolaridade e a concepção de Educação Física que eram presentes no século passado podemter sido fatores que contribuíram para 0 fortalecimento do vínculo com a disciplina, ao mesmo tempo em que provocaramo sentimento de negaçãoda atividade com o esporte de alto rendimento, quando do ingresso na escola.

$\mathrm{Na}$ vida da professora de Educação Física, a formação continuada pautou-se pela motivação em continuar estudando, em superar os desafios que surgiam e pela busca por constante atualização. Ao investigar professores de Educação Física da rede pública estadual do Rio de Janeiro, Ferreira, Santos e Costa (2015) também constataram que professores experientes priorizam a participação em eventos na área pedagógica, visando a uma formação coerente com seu lócusde intervenção profissional. Nesse sentido, Rossi e Hunger (2012) indicam que a formação continuada realmente contribui para o aperfeiçoamento e a qualificação da ação docente, além de fornecer subsídiosante novos desafios profissionais.

No que tange ao percurso profissional, destaca-se que os modelos de ciclo de vida da carreira docente são descritivos, uma vez que eles procuram descrever uma progressão de fases de desenvolvimento e de crescimento dos professores em sua profissão (STEFFY et al., 2000).De modo similar, Huberman (2000) apresenta um modelo descritivo de fases da vida docente, mesmo reconhecendo que no desenvolvimento profissional de professores pode haver progressões e regressões, dependendo de como cada professor reage às suas experiências. Para tanto, a análise dos ciclos do percurso profissional da professora emérita pautou-se nas teorias apresentadas por Nascimento e Graça (1998), Gonçalves (2000), Huberman (2000), Steffy et al. (2000) e Farias e Nascimento (2012), cabendo destacar que a única classificação que retrata a fase Emérita é a proposta por Steffy et al. (2000). Sendo assim, esta consolidou as análises e possibilitou discorrer sobre os tempos anteriores da carreira e o seu momento atual.

Nesse sentido, as informações obtidas sobre os ciclos de vida docente da professora emérita revelaram momentos marcantes dos ciclos de Entrada; Consolidação; Afirmação e 
Diversificação; Renovação; e da fase Emérita. $O$ ciclo de Entrada (até 4 anos) foi marcado pelo sentimento de distanciamento entre a formação inicial e a entrada na carreira, o choque com o real e a tomada de decisão em torno da profissão escolhida.

Tal percepção de sobrevivência, marcada, principalmente, pelo choque com a realidade e pela percepção de distância entre aprendizagens da formação e mercado de trabalho, é referendada em estudos realizados com professores de Educação Física (FOLLE et al., 2009; FOLLE; NASCIMENTO, 2010; MEDEIROS et al., 2014; FARIAS; NASCIMENTO, 2012; ZULJAN; POZARNIK, 2014; CARDOSO; BATISTA; GRAÇA, 2016). Todavia, Medeiros et al. (2014) refletem que, muitas vezes, a concepção sobre a relação entre o curso superior e 0 ingresso no magistério está ancorada no entendimento de que a formação inicial deve dar conta de preparar os professores para todos os problemas esituações enfrentadas no cotidiano educativo, mas quando sedão por conta de que isso não corresponde à realidade, iniciam um processo de culpabilização de seu processo formativo, perante o desenvolvimento profissional docente. A ideia de culpabilização não traz um sentido negativo para o curso superior, mas destaca aspectos que não foram compreendidos ou delineados pelos estudantes durante sua formação inicial. Talvez, este processo esteja alicerçado na dificuldade do entendimento do conceito de docência adquirido nos cursos de licenciatura, o que faz com que o futuro professor ainda apresente dúvidas quanto ao ato de ensinar e ao exercício da sua função.

Os momentos marcantes vivenciados no ciclo de Consolidação das Competências Profissionais despertaram uma paixão maior pelo ensino e um sentimento maior de confiança em torno da gestão dos processos educativos. Tais sentimentos são expressos como característicos de um segundo período vivenciadopelos professores, após ingressarem em suas trajetórias profissionais. Para Gonçalves (2000), nessa segunda etapa os professores "assentam os pés no chão", alcançando maior confiança e demonstrando maior gosto pelo ensino e domínio do processo ensino e aprendizagem, enquanto Huberman (2000) enfatiza que essa fase evidencia um comprometimento definitivo, uma estabilização ou uma tomada de responsabilidade. De modo similar, Farias e Nascimento (2012, p. 72) ressaltam que "[...] os professores compreendem melhor sua profissão, conseguem diversificar sua prática pedagógica e se sentem mais valorizados por seus pares. [...] manifestam o desejo de permanência na carreira e planejam ações futuras que irão incidir na qualificação profissional e no crescimento pessoal".

O fortalecimento das relações com os colegas de trabalho, a variação das ações pedagógicas e a diversificação das funções assumidas, especialmente em cargos administrativos, são momentos marcantes do ciclo de Afirmação e Diversificação da Carreira vivenciada pela docente emérita, e característicos da terceira fase do desenvolvimento profissional, proposta na literatura (NASCIMENTO; GRAÇA, 1998; GONÇALVES, 2000; HUBERMAN, 2000; FARIAS; NASCIMENTO, 2012). Destaca-se ainda que Folle e Nascimento (2010) e Nunes e Godoi (2013) também verificaram junto a professores de Educação Física que as funções administrativas de confiança e comissionadas se tornam uma constante do desenvolvimento profissional nesta área.

O ciclo de Renovação na Carreira, segundo Farias e Nascimento (2012), concretiza-se pela aproximação da fase de aposentadoria, apresentando duas vertentes: professores que insistem na permanência no ensino por estarem ainda em uma fase produtiva e professores que necessitam completar mais alguns anos de tempo de serviço para se aposentar. Enfatiza- 
se que a professora de Educação Física investigada, por possuir tempo de atuação profissional suficiente para a aposentadoria na rede estadual de educação, optou por solicitá-la.

No entanto, as marcas desta decisão resultaram na perda de identidade, a qual provocou um adoecimentoemocional em função do afastamento da escola. Essa crise foi superada com a continuidade da carreira na rede pública municipaleo ingresso na fase Emérita da carreira docente. Esse fato demonstra que, no momento da aposentadoria, a professora se encontrava na fase de renovação, com características de encantada com a profissão e renovadora da sua atuação profissional, reportando que a docência ainda instigava investimento de sua parte.

Ao investigarem as experiências e as perspectivas de distintos profissionais aposentados, Fontoura, Doll e Oliveira (2015) identificaram aqueles cujo afastamento provocou o sentimento de sofrimento e aqueles que, com a saída do trabalho, dedicaram-se a outras atividades, as quais durante a vida profissional não tiveram oportunidade de concretizar. Neste caso, a percepção negativa de sentimento dá-se pelo fato dos profissionais não incorporarem a ideia de aposentadoria ou não se prepararem emocionalmente para a ruptura do mundo do trabalho, enquanto a percepção positivaocorre mediante as diversas possibilidades prazerosas e significativas, para além do trabalho, encontradas após a aposentadoria e para as quais passam a desfrutar de maior tempo.

Entretanto, Moreira, Barros e Silva (2014, p. 124) refletem queaatuação no ambiente de trabalho possibilita ao docente ampliar suas relações e sua identidade social, bem como define elementos constituintes de sua identidade pessoal. Desse modo, a aposentadoria para muitos professores, pertencentes a uma "[...] sociedade que idolatra o trabalho e a produção", pode representar uma perda inestimável, inclusive do próprio sentido de sua vida, uma vez que a atividade laboral afeta os aspectos emocionais do trabalhador, representando a perda de referências e a sua identificação pessoal. Fato este que ocorreu com a professora investigada, que, ao se afastar da escola em que atuou por tantos anos (criou vínculos e obteve conquistas profissionais), percebeupaulatinamente a perda da sua identidade docente, ocasionada pela presença de outras pessoas suprindo sua ausência na escola, o que reforçou o sentimento de perda do sentido da sua vida.

Contrariamente aos achados desta investigação, professores de Educação Física aposentados ou em final de carreira investigados por Betti e Mizukami (1997), Folle et al. (2009), Santos, Bracht e Almeida (2009), Folle e Nascimento (2010) e Porath et al. (2011) revelaram que a proximidade da conquista da aposentadoria docente é vivida com sentimento de desinvestimento profissional, seja ele sereno ou amargo, mas com o desejo de findar a carreira e buscar novas alternativas pessoais e profissionais.Todavia, o desejo de permanecer ativa no contexto que se desenvolveu profissionalmente, resultante da satisfação com sua profissão, se aproxima dos achados de investigações com professores universitários brasileiros (HOPF; CANFIELD, 2001; MOREIRA; BARROS, SILVA, 2014).

Neste contexto, as investigações revelam que os professores atuantes na Educação Básica, a partir da reflexão em torno de suas experiências profissionais, não perspectivam retornar ao ambiente escolar após a aposentaria. Por outro lado, a professora investigada apresenta um novo panorama para a realidade deste nível de ensino, similar ao que acontece no ensino superior, pois o sentimento de permanência na carreira docente reportado por ela está relacionado, especialmente, à satisfação com suas experiências de sucesso ao longo de sua vida profissional. 
Esta fase atual em que a professora de Educação Física se encontra (aposentada, mas ativa em escola de Educação Básica) reflete ainda o sentimento de realização com a profissão, a contribuição com a educação e o desejo em permanecer ativa. Nesse cenário, revela-se que o sentimento de ter vivenciado um percurso profissional de sucesso influenciou determinantemente o desenvolvimento da carreira docente da professora de Educação Física, ocasionando o anseio em permanecer na profissão ao longo dos diferentes ciclos de vida docente, em especial, no período de transição entre as etapas de Renovação e Emérita.

Compreende-se, assim, que a fase Emérita distingue o professor aposentado, no que tange ao desejo de continuidade na carreira docente e a possibilidade de socializar os seus conhecimentos com os professores mais jovens (DAGENAIS; STEFFY; ENZ, 2000; STEFFY et al., 2000). Além disso, Camaro, Kanso e Farnandes (2013, p. 28) enfatizam que após a aposentadoria, alguns indicadores que favorecem a permanência no trabalho são: "[...] saída precoce da atividade econômica, boas condições de saúde e autonomia".

Reflete-se que tais fatores se aproximam dos apontados pela investigada, haja vista que ela tenha perspectivado a possibilidade de reduzir a carga horária e, mesmo assim, manter uma estabilidade financeira. Todavia, o que se sobressai em sua narrativa corresponde ao gosto pela profissão e o prazer em lecionar.Assim, a permanência da professora na carreira deteve-se na perspectiva de ainda permanecer ativa no ensino, considerando o seu desejo de continuidade no contexto laboral, manifestado pelo sentimento de competência profissional docente e representatividade entre os pares.

\section{CONCLUSÕES}

O estudo sobre a história de vida da professora emérita resultou na análise dos percursos pessoal, formativo e profissional, evidenciando assim aspectos importantes sobre 0 processo de desenvolvimento da carreira docente em Educação Física. Apesar das limitações encontradas na investigação desta históriade vida, tais como a contemplação de toda a riqueza de uma trajetória, a partir das recordações armazenadas na memória e enunciadas na narrativa de apenas uma professora, as informações obtidas possibilitam apresentar informações relevantes para compreensão das implicações do eu pessoal e profissional nos significados atribuídos às experiências daqueles que se dedicam, até mesmo após a aposentadoria, ao ensino de crianças e adolescentes de escolas públicas.

A análise da narrativa da professora apresentou o percurso pessoal marcado pelo afastamento do convívio familiar em diversos momentos da vida em virtude dos estudos e de novas oportunidades profissionais. 0 percurso formativofoicaracterizado pelas experiências positivas com o esporte na Educação Básica, com o encantamento com o curso de graduação e com a constante busca de atualização.

O percurso profissional foi sustentado pelos momentos significativos que marcaram os ciclos de vida da carreira docente, em que se destacaram o choque com o real, a conquista pela efetivação em duas redes de ensino, as experiências diversificadas e o adoecimento advindo da aposentadoria. A continuidade da trajetória docente está pautada na realização profissional, no encantamento com a docência e no desejo de permanecer ativa.

Por fim, conclui-se que investigar uma carreira docente a partir do olhar da história de vida de uma professora que percorreu todos os ciclos da vida docente e permanece ativa 
no magistério constitui-se como o mérito do estudo, haja vistaqueprofessores inseridos na faseEmérita são distintos de saberes, competências e realizações profissionais que motivam a sua condição de docentes ativos. Da mesma forma que sentir-se ativo e com experiência alargada na docência transforma-se no contributo primordial para a compreensão da fase emérita da carreira docente.

As informações sobre uma história de vida única e pessoal instigam a curiosidade investigativa para ampliação de pesquisas sobre 0 desenvolvimento profissional de docentes aposentados, tanto dos que retornaram às salas de aula quanto daqueles que se afastaram definitivamente das escolas públicas, para melhor compreensão das possíveis nuances que levam os professores a estas tomadas de decisão.O desafio está centrado, justamente, na proposição de estudos que, para além das fases, ciclos ou estágios de desenvolvimento profissional declarados nas teorias que delinearam esta pesquisa, compreendam os docentes que ultrapassaram os tempos da carreira docente, mas almejam a continuidade de seu percurso profissional.

\section{REFERÊNCIAS}

ALMEIDA, Luciano de; FENSTERSEIFER, Paulo Evaldo. Professoras de Educação Física: duas histórias, um só destino. Movimento, v. 13, n. 2, p. 13-35, maio/ago. 2007.

BARDIN, Laurence. Análise de conteúdo. Lisboa: Edições 70, 2011.

BENITES, Larissa Cerignoni; SOUZA NETO, Samuel. Educação Física, professores e estudantes: a escolha da docência como profissão e os saberes que lhe são constitutivos. Pensar a Prática, v. 14, n. 2, p. 1-11, maio/ago. 2011.

BETTI, Irene Rangel; MIZUKAMI, Maria da Graça Nicoletti. História de vida: trajetória de uma professora de Educação Física. Motriz, v. 3, n. 2, p. 108-115, dez. 1997.

CAMARANO, Ana Amélia; KANSO, Solange; FERNANDES, Daniele. Saída do Mercado de trabalho: qual é a idade? Mercado de Trabalho: conjuntura e análise, v. 17, n. 51, p. 20-28, 2012.

CARDOSO, Inês; BATISTA, Paula; GRAÇA, Amândio. A identidade do professor de Educação Física: um processo simultaneamente biográfico e relacional. Movimento, v. 22, n. 2, p. 523538, abr./jun. 2016.

DAGENAIS, Raymond J.; STEFFY, Betty E.; ENZ, Billie J. The emeritus teacher. In: STEFFY, Betty E. et al.Life cycleofthecareerteacher. Indianapolis: Kappa Delta Pi, 2000. p. 96-103.

FARIAS, Gelcemar Oliveira; NASCIMENTO, Juarez Vieira do. Construção da identidade profissional: metamorfoses na carreira docente em Educação Física. In: NASCIMENTO, Juarez Vieira do; FARIAS,Gelcemar Oliveira (Org.). Construção da identidade profissional em Educação Física: da formação à intervenção. Florianópolis: Ed. UDESC, 2012. p. 61-77.

FERREIRA, Janaína da Silva; SANTOS, José Henrique dos; COSTA, Bruno de Oliveira. Perfil de formação continuada de professores de Educação Física: modelos, modalidades e contributos para a prática pedagógica. Revista Brasileira de Ciências do Esporte, v. 37, n. 3, p. 289-298, 2015. 
FOLLE, Alexandra et al. Construção da carreira docente em Educação Física: escolhas, trajetórias e perspectivas. Movimento, v. 15, n. 1, p. 25-49, jan./mar. 2009.

FOLLE, Alexandra; NASCIMENTO, Juarez Vieira do. Trajetória docente em Educação Física: percursos formativos e profissionais. Revista Brasileira de Educação Física, v. 24, n. 4, p. 507-523, out./dez. 2010.

FONTOURA, Daniele dos Santos; DOLL, Johannes; OLIVEIRA, Saulo Neves de. O desafio de aposentar-seno mundo contemporâneo. Educação \& Realidade, v. 40, n. 1, p. 53-79, jan./mar. 2015.

GONÇALVES, José Alberto. A carreira das professoras do ensino primário. In: NÓVOA, Antônio. Vidas de professores. 2. ed. Porto: Porto Editora, 2000. p. 143-169.

HEBERT, Edward; WORTHY, Terry. Does the first year of teaching have to be a bad one? A case study of success.Teaching and Teacher Education, v. 17, n. 8, p. 897-911, Nov. 2001.

HUBERMAN, Michaël. O ciclo de vida profissional dos professores. In: NÓVOA, Antônio. Vidas de professores. 2. ed.Porto: Porto Editora, 2000.p. 33-61.

HUTCHINSON, Gayle; BUSCHNER, Craig. Delayed-entry undergraduates in Physical Education teacher education: examining life experiences and career choice. Journal of Teaching in Physical Education, v. 15, n. 2, p. 205-223, Jan. 1996.

JUNGES,Kelen dos Santos. Trajetória de vida, constituição profissional e autonomia de professores. União da Vitória: FACE, 2006.

KOCHHANN, Bernardete Maria Gerhardt. Os caminhos de um sonho. In: MARTINAZZO, Celso José. História de vida de professores: formação, experiência e práticas. ljuí: Ed. UNIJUÍ, 2000. p. 4-77.

MACHADO, Thiago da Silva et al. As práticas de desinvestimento pedagógico na Educação Física Escolar. Movimento, v. 16, n. 2, p. 129-147, abr./jun. 2010.

MEDEIROS, Camila da Rosa et al. Identização docente de professores de Educação Física no início da carreira. Educação em Perspectiva,v. 5, n. 2, p. 31-49, jul./dez. 2014.

MOLETTA, Andreia Fernanda et al. Momentos marcantes do Estágio Curricular Supervisionado na formação de professores de Educação Física. Pensar a Prática, v. 16, n. 3, p. 715-730, jul./ set. 2013.

MONTEIRO, Filomena Maria de Arruda; MIZUKAMI, Maria da Graça Nicoletti. Professoras das séries iniciais do ensino fundamental: percursos e processos de formação. In: MIZUKAMI, Maria da Graça Nicoletti; REALI, Aline Maria de Medeiros Rodrigues. Formação de professores, práticas pedagógicas e escola. São Carlos: EdUFSCar, 2002. p. 175-201.

MOREIRA, Jacqueline de Oliveira; BARROS, Flávia Moreira Barroca de; SILVA, Jose Mauricio da. Aposentadoria e exercício profissional: um encontro possível para os professores de uma universidade católica. Psicologia Argumento,v. 32, n. 79, p. 123-130, 2014.

NASCIMENTO, Juarez Vieira do; GRAÇA, Amândio. A evolução da percepção de competência profissional de professores de Educação Física ao longo da carreira docente. In: CONGRESSO DE EDUCAÇÃO FÍSICA E CIÊNCIAS DO DESPORTO DOS PAÍSES DE LÍNGUA PORTUGUESA, 6., 1998. La Coruña.Actas... La Coruña: INEF Galícia, 1998. v.1, p. 320-335. 
NUNES, Rozicleiton Magalhães; GODOI, Marcos Roberto. História de vida, formação e desenvolvimento profissional de um professor de Educação Física das redes públicas de Educação. Revista Mackenzie de Educação Física e Esporte, v. 12, n. 1, p. 156-172, 2013.

PORATH, Margareth et al. Fase de desinvestimento na carreira docente de professores de Educação Física. Movimento, v. 17, n. 4, p. 203-222, out./dez. 2011.

ROCKENBACH, Arnildo Laurencio.Trajetória de formação e atuação: um olhar reflexivo. In: MARTINAZZO, Celso José. História de vida de professores: formação, experiência e práticas. ljuí: Ed. UNIJUÍ, 2000. p. 15-46.

ROSSI, Fernanda; HUNGER, Dagmar. As etapas da carreira docente e o processo de formação continuada de professores de Educação Física. Revista Brasileira de Educação Física e Esporte, v. 26, n. 2, p. 323-38, abr.jun. 2012.

SANTOS, Núbia Zorzanelli dos; BRACHT, Valter; ALMEIDA, Felipe Quintão de. Vida de professores de Educação Física: o pessoal e o profissional no exercício da docência. Movimento, v. 15, n. 2, p. 141-165, abr./jun. 2009.

SOUZA, Elizeu Clementino de. A arte de contar e trocar experiências: reflexões teóricometodológicas sobre história de vida em formação. Revista Educação em Questão,v. 25, n. 11, p. 1-39, jan./abr. 2006.

STEFFY, Betty et al. The model and its application.In: STEFFY, Betty et al.Life cycle of the career teacher.Indianapolis: Kappa Delta Pi, 2000. p. 1-25.

ZULJAN, Milena Valenčič; POŽARNIK, Barica Marentič. Induction and early-career support of teachers in Europe.European Journal of Education, v. 49, n. 2, p. 192-205, 2014. 
